\title{
Mechanical Characterization of Recycled Aggregates Concrete Based on its Compressive Strength
}

\author{
Khaoula Naouaoui*, Toufik Cherradi \\ Mohammadia School of engineers, Mohamed V University Agdal, Rabat, 10000, Morocco
}

\begin{tabular}{l} 
A R T I C L E I N F O \\
\hline Article history: \\
Received: 23 December, 2020 \\
Accepted: 12 April, 2021 \\
Online: 05 May, 2021 \\
\hline
\end{tabular}

Keywords:

Concrete

Mechanical properties

Natural aggregates

Recycled aggregates

Replacement percentage

\begin{abstract}
A B S T R A C T
The construction industry has undergone several changes in recent years linked to new laws and international conventions aimed at protecting the environment and combating pollution. Construction industry alone produces tons of waste annually due to debris produced either during construction or during deconstruction. To combat this, companies are forced to control their debris either by reusing it on site or by sending it to specialized landfills. Thus, new materials appear constantly based on the recycled materials. Recycled aggregate concrete was thus born. It is a concrete based on the use of recycled aggregates retrieved from the demolished structures to replace natural aggregates. Characteristics of this type of concrete depends of the chosen replacement percentage of natural aggregates specially the mechanical properties. This article is part of my research studies done in the civil laboratory of the Mohammadia School of engineers. The study is based on the identification of the recycled aggregates, the determination of physicals and mechanical characteristics of the aggregates, the determination of the effect of the use of recycled aggregates on the concrete characteristics and finally the improve of the quality of the concrete to prove so that it can replace ordinary concrete. The test results described in this article show that the increase of the replacement by recycled aggregates decreases the mechanical properties especially when it is up to $25-30 \%$. The results also prove that the ad of additives especially plasticizer with $1 \%$ replacement of cement improves the compressive strength of concrete and allows us to use up to $50 \%$ of replacement.
\end{abstract}

\section{Introduction}

The field of construction knows a radical undergoing and innovative changes in the designs proposed, the types of materials used and the domains of their use. Concrete, as the main construction material, is now at the center of several studies, researches, innovations and improvements. Several types of new concrete are proposed for their quality, compliance with environmental and / or technical requirements, design and special needs. One of the concrete types proposed for their environmental value, their support for sustainable development is the recycled aggregates concrete.

The comparison of its properties with those of concrete based on naturel aggregates. A summary of the comparison between the two concretes is detailed below:

Related to the compressive strength, the majority of studies confirm that up to [20-30] percentage replacement of natural aggregates by recycled ones, the compressive strength is almost

"Corresponding Author: Khaoula Naouaoui, naouaoui.khaoula@gmail.com the same but beyond this replacement level, it decreases considerably. Main recent studies results are as folow.

Many experimental studies match our synthesis that up to $25 \%$ the compressive strength is the same and that the decrease's max is $20 \%$ for $100 \%$ replacement level [1]. Others conducted a synthesis of several researches and works in his article. He concluded that in case compressive strength values of the original concrete, of which recycled aggregate is manufactured, and targeted values were approximately equal. The strength values of recycled aggregate concrete was 5 to $10 \%$ lower than those of the comparable naturel aggregate concrete were [2].

For the modulus of elasticity, the experimental studies prove that its values have almost the same trend as compressive strength results. The increase in insignificant for percentage level up to 75 $\%(9 \%)$ and it reaches $18 \%$ for $100 \%$ replacement of natural aggregates by recycled ones [1]. In another study, they found a reduction of $34.8 \%$ when the replacement level is $100 \%$ compared to the control concrete [3]. Meanwhile, other researchers found 45 $\%$ of reduction for the same replacement level. [4] 
Studies done on durability properties as open porosity, sorptivity, chloride permeability confirm that they decrease with the increase of RCA content. The study also concluded that the rate of deterioration is higher compared to mechanical characteristics.

For example, for $100 \%$ replacement level, the resistance to chloride permeability decrease by $9.5 \%$ [5], the water absorption is lower by $7.37 \%$ [3] and the open porosity by $20 \%$ [6].

\section{Experimental Protocol}

This section is related to the description of the experimental protocol done to determinate the mechanical properties of concrete based on the restitution of the natural aggregates by recycled one.

\subsection{Concrete formulation to determinate the constituents}

The main of our study is to determine the possibility of replacing naturel concrete by recycled aggregates concrete in the majority of types of building, thus the concrete chosen to study have the following characteristics:

- Basic concrete, ordinary, used in all types of based constructions.

$-\mathrm{F}_{\mathrm{c} 28}=25 \mathrm{MPA}$.

- Slump: Average of $7 \mathrm{~cm}$.

To formulate this concrete, the constituents chosen are:

For aggregates, we have chosen two aggregate, the first are natural ones and the second recycled aggregates based on a crushed building. For the two of them we used two dimensions: [512.5] and [12.5-31.5]

The result of the granulometric test of the two aggregates is presented in the figure 1 :

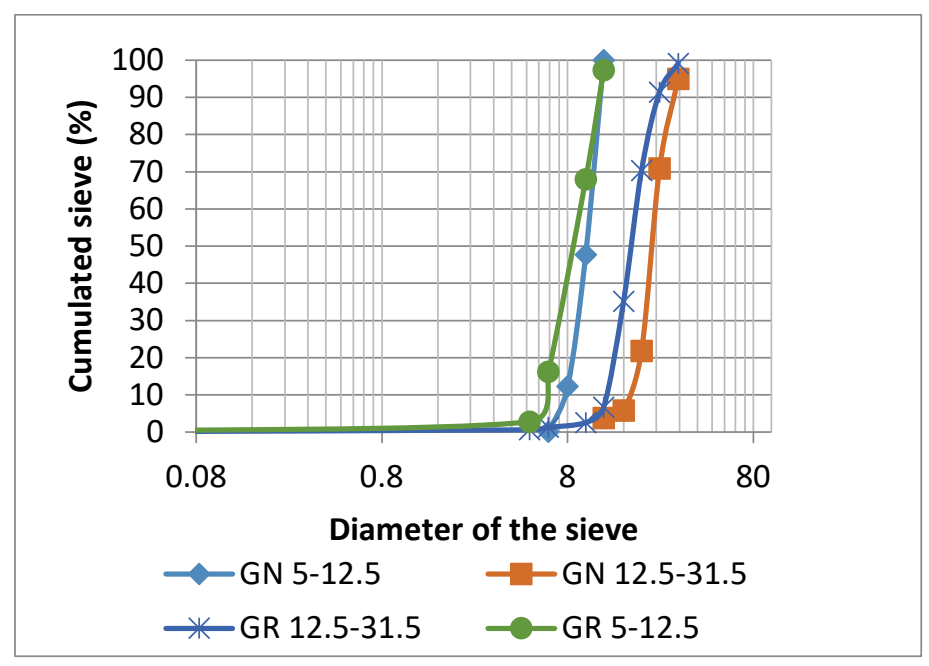

Figure 1: Granometric curve for natural and recycled aggregates used in experimental study (GN : Naturel gravel / GR : recycled gravel).

The quantities of materials used based on the dreux gorisse method [7] are, as follows:

- Water : $0.19 \mathrm{~m}^{3} / 190 \mathrm{~kg}$

- Cement : $0.29 \mathrm{~m}^{3} / 350 \mathrm{~kg}$

- $\quad$ Sand : $0.29 \mathrm{~m}^{3} / 472.85 \mathrm{~kg}$
- Gravillon G1 : $0.15 \mathrm{~m}^{3} / 376.14 \mathrm{~kg}$

- Gravillon G2 : $0.2 \mathrm{~m}^{3} / 537.3 \mathrm{~kg}$

\subsection{Concrete mixtures}

The aim of the study is to detect the effect of the replacement percentage of natural aggregates by recycled aggregates in the compressive strength of concrete and the effect of different types of additives in improving the mechanical characterisation of theses concretes.

The replacement ratio studied are $0 \%-20 \%-50 \%-75 \%-$ $100 \%$.

For the mixture with additives, we used three product from SIKA- MAROC:

- Plasticizer/ water reducer: BV40

- Superplasticizer/ high water reducer: ViscoCrete Tempo $10 \mathrm{M}$

- New generation superplasticizer: SikaFluid R.

The first step of experimental study was as explained before, the effect of the replacement of naturel aggregates by recycled ones. The quantity of component used for every mixture in detailed in the table.

Table 1: Quantity used in the compressive strength test ( $\mathrm{kg}$ )

\begin{tabular}{|c|c|c|c|c|c|c|c|}
\hline \multicolumn{2}{|c|}{ Component } & $\begin{array}{l}0 \% \\
\text { GR }\end{array}$ & $\begin{array}{l}20 \% \\
G R\end{array}$ & $\begin{array}{l}30 \% \\
\text { GR }\end{array}$ & $\begin{array}{l}50 \\
\% \\
\text { GR }\end{array}$ & $\begin{array}{l}75 \% \\
\text { GR }\end{array}$ & $\begin{array}{l}100 \\
\% \\
\text { GR }\end{array}$ \\
\hline \multicolumn{2}{|c|}{ Cement } & \multicolumn{6}{|c|}{350} \\
\hline \multicolumn{2}{|c|}{ Water } & \multicolumn{6}{|c|}{193} \\
\hline \multicolumn{2}{|c|}{ Sand } & \multicolumn{6}{|c|}{473} \\
\hline \multirow{2}{*}{ GN } & $\begin{array}{l}5- \\
12.5\end{array}$ & 402 & 321,6 & 281,4 & 201 & 100,5 & 0 \\
\hline & $\begin{array}{l}12.5- \\
31.5\end{array}$ & 512 & 409,6 & 358,4 & 256 & 128 & 0 \\
\hline \multirow{2}{*}{ GR } & $\begin{array}{l}5- \\
12.5\end{array}$ & 0 & 80,4 & 120,6 & 201 & 301,5 & 402 \\
\hline & $\begin{array}{l}12.5- \\
31.5\end{array}$ & 0 & 102,4 & 153,6 & 256 & 384 & 512 \\
\hline
\end{tabular}

The second step of study was to determinate the effect of additives in improving the concrete quality. To do this, we used three types of adjuvants with different percentages. The experimental protocol is as details below:

The test aims to view the effect of the ad of superplasticizer on the comparison between different replacement levels by calculating the compressive strength for various replacement levels with the superplasticizer. The component is similar to the previous one; it is based on using different percentages of replacement of natural aggregates by recycled one. The only difference is the use of superplasticizer.

Second part of the study is to determinate the Compressive strength with different adjuvants. For this comparative test, we 
used a concrete based on $50 \%$ of recycled aggregates and $50 \%$ of natural aggregates. We, then, added the three types of adjuvant with $1 \%$ of replacement of cement with means $3.5 \mathrm{~kg} / \mathrm{m}^{3}$ of concrete.

The last step of comparison is the Compressive strength with different percentages of the adjuvant. For this comparative test, we used different percentage of the Tempo $10 \mathrm{M}(0.5 \%, 1 \%$ and $1.5 \%)$ as a partial replacement of cement. The concrete used is based on $50 \%$ of recycled aggregates and $50 \%$ of natural aggregates.

\section{Experimental results and discussions}

\subsection{Physical characterization of recycled aggregates}

The physical characterization of aggregates from the demolition of an old building can be summarized as detailed below.

Table 2: Summarize of the physical characterization tests

\begin{tabular}{|l|c|l|}
\hline & $\begin{array}{l}\text { Recycled } \\
\text { aggregates 5-12.5 }\end{array}$ & $\begin{array}{l}\text { Recycled } \\
\text { aggregates 12.5- } \\
31.5\end{array}$ \\
\hline Absolute Density & \multicolumn{2}{|c|}{$2480 \mathrm{~kg} / \mathrm{m}^{3}$} \\
\hline Water content & $1.49 \%$ & $4.32 \%$ \\
\hline $\begin{array}{l}\text { Water } \\
\text { absorption }\end{array}$ & $11.11 \%$ & $9.4 \%$ \\
\hline
\end{tabular}

The absolute density is $2.48 \mathrm{t} / \mathrm{m}^{3}$ approximatively $2.5 \mathrm{t} / \mathrm{m}^{3}$ wich is the absolute density of reinforced concrete.

The comparison between two recycled aggregates of two different classes GR1 (5-12.5) and GR2 (12.5-31.5) showed that the water content is greater for large aggregates. This is justified by the presence of several pores which disappear during fine crushing of the aggregates.

The comparison has also shown that the water absorption rate is higher for small aggregates. This is justified by the superiority of the contact surface.

\subsection{Compressive strength without additives}

The aim was to determinate the effect of the replacement percentage on the compressive strength, so we made mixtures with $0,20,30,5075$ and $100 \%$ replacement percentage.

The results of compressive strength in 7, 21, 28 and 90 days are detailed in Table 3.

Table 3: Compressive strength results for concrete without additives (MPA)

\begin{tabular}{|c|c|c|c|c|c|c|}
\hline & $\begin{array}{c}0 \% \\
\text { RA }\end{array}$ & $\begin{array}{c}20 \% \\
\text { RA }\end{array}$ & $\begin{array}{c}30 \% \\
\text { RA }\end{array}$ & $\begin{array}{c}50 \% \\
\text { RA }\end{array}$ & $\begin{array}{c}75 \% \\
\text { RA }\end{array}$ & $\begin{array}{c}100 \% \\
\text { RA }\end{array}$ \\
\hline $7 \mathrm{j}$ & 16,5 & 14,65 & 16,75 & 13,55 & 14,05 & 14,5 \\
\hline $21 \mathrm{j}$ & 23,4 & 19,9 & 14,8 & 14,3 & 19 & 14,7 \\
\hline $28 \mathrm{j}$ & 24,8 & 23,55 & 23,5 & 18,05 & 17,7 & 15 \\
\hline $90 \mathrm{j}$ & 26,3 & 25,35 & 23,55 & 20,25 & 19,4 & 17,8 \\
\hline
\end{tabular}

In order to make the comparison easier and more remarkable, a j-day compression graph for all replacement percentages was established. ( figure2)

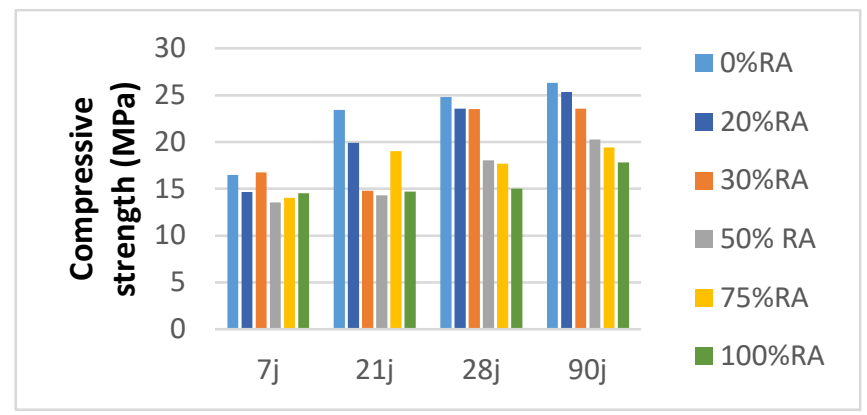

Figure 2: Compressive strength test results representation

At early age, 7 and 28 days, the resistance to compression cannot be decisive because the inter-component reactions are still in progress, so we can notice that the evolution of the resistance for mixtures with 0 or $20 \%$ restitution is greater than the others. For concrete containing 30\% natural aggregates, it is noted that the compression at 7 days is greater than that of 21 days. This is probably due to poor sampling and that not reflects a real decrease in compression.

28 days is considered to be the reference for resistance in the short and medium term because the compression reaches $90 \%$ of its maximum value. The results at 28 days in our study are similar to the majority of researchers. The compressive strength decreases with increasing replacement rate.

After compression tests on recycled aggregate concrete with different percentages, it has been found that beyond $50 \%$, an improvement in quality is required to adopt this type of concrete.

The first proposal to improve this is to add an additive that reduces the water requirement of the aggregates and thus improves the quality of the concrete.

In order to determine the best combination (type of adjuvant and percentage of addition), a series of mixtures are proposed:

- Concrete with $50 \%$ recycled aggregates and $1 \%$ added admixture with different types of admixture.

- Concrete with 50\% recycled aggregates and one type of adjuvant with different percentage of adjuvant added.

- Concrete with several recycled aggregate's percentage and one type and percentage chosen for adjuvant.

\subsection{Compressive strength with different adjuvants}

The purpose of this step is to compare the effect of several types of adjuvants with a percentage of $1 \%$.

These adjuvants are of several types:

- Plasticizer: BV 40

- Superplasticizer: Tempo $10 \mathrm{~m}$

- New generation superplasticizer: SFR

The choosen percentage of recycled aggregates for this test is $50 \%$ as replacement of natural aggregates. 
Compression tests are done at 7 and 28 days. The results are detailed in table 6.

Table 4: Compressive strength results for concrete with various additives (MPa)

\begin{tabular}{|c|c|c|}
\hline Type of adjuvant & $\begin{array}{c}\text { Compressive } \\
\text { strength at 7 days }\end{array}$ & $\begin{array}{c}\text { Compressive } \\
\text { strength at 28 days }\end{array}$ \\
\hline BV40 & 19,87 & 22,63 \\
\hline SFR & 11,50 & 16,65 \\
\hline Tempo 10 M & 17,47 & 21,45 \\
\hline
\end{tabular}

From the results of these tests, it is noted that:

- $\quad$ The new generation superplasticizer gives the lowest result. This can be interpreted as a bad interaction between the aggregates and their cement paste attached with the additive.

- The plasticizer gives the best resistance

- The superplasticizer also gives a good result, better than without additives.

\subsection{Compressive strength with different percentages of the adjuvant}

These tests aim at the optimal choice of the percentage of the adjuvant in the mixture.

The results of these tests demonstrate that beyond $1 \%$, compression decreases considerably.

Then, for our next mixes, the chosen percentage is $1 \%$.

Table 5: Compressive strength results for concrete with different percentage of additive ( $\mathrm{MPa})$

\begin{tabular}{|l|c|c|c|}
\hline $\begin{array}{c}\text { Type of } \\
\text { adjuvant }\end{array}$ & $\begin{array}{c}\text { Percentage } \\
\text { of adjuvant }\end{array}$ & $\begin{array}{c}\text { Compressive } \\
\text { strength at 7 } \\
\text { days }\end{array}$ & $\begin{array}{c}\text { Compressive } \\
\text { strength at 28 } \\
\text { days }\end{array}$ \\
\hline \multirow{3}{*}{$\begin{array}{c}\text { Tempo 10 } \\
\text { M }\end{array}$} & $0,5 \%$ & 14,35 & 19,90 \\
\cline { 2 - 4 } & $1,0 \%$ & 17,47 & 21,45 \\
\hline
\end{tabular}

\subsection{Compressive strength for various replacement levels with}

the superplasticizer

The purpose of this part of the tests is to see the result of the combination of the adjuvant tempo10M - percentage $1 \%$ with various percentages of recycled aggregates.

Table 6: Compressive strength results for concrete with additive (MPa)

\begin{tabular}{|c|c|c|}
\hline percentage of RA & $\begin{array}{l}\text { Compressive } \\
\text { strength at 7 days }\end{array}$ & $\begin{array}{l}\text { Compressive } \\
\text { strength at 28 days }\end{array}$ \\
\hline 25 & 18,33 & 24,3 \\
\hline 50 & 17,47 & 21,45 \\
\hline 75 & 14,5 & 20,47 \\
\hline 100 & 14,3 & 19,65 \\
\hline
\end{tabular}

We conclude that these tests adhere to the results of concrete without additives where compression decreases with increasing percentage of recycled aggregates.

\subsection{Conclusion}

The plasticizer (BV40) as well as this superplasticizer (Tempo $10 \mathrm{M}$ ) with a percentage of $1 \%$ improves the compressive strength: 18.05 for concrete with $50 \%$ recycled aggregates without addition, 22.63 with addition of BV40 and 21.45 with addition of Tempo 10 M.

\section{Conclusion and Perspectives}

Our article summarizes the results of experimental works conducted as part of a $\mathrm{PhD}$ research on the characterization of recycled aggregates.

The tests focus on the mechanical characterization and essentially the compression test, considered essential in any concrete study.

It was split in four steps: Test on ordinary concrete with various percentages of natural aggregates with and without adjuvant, tests on concrete with $50 \%$ recycled aggregates with different additives and with different percentages of admixtures.

The results show that:

- Compression decreases with increasing percentage of recycled.

- Up to $30 \%$ replacement of natural by recycled aggregates, the concrete is acceptable from a mechanical characterization point of view

- $\quad$ The addition of plasticizer and superplasticizer has improved the quality of the concrete. This can be explained by the fact that recycled aggregates require more water and these additives reduce this need.

- The optimum percentage of addition of the plasticizer is $1 \%$

A review of the literature shows that one of the main methods to improve the quality of concrete is to improve the quality of aggregates by removing the adhered mortar, causing higher water absorption and chemical interaction with other concrete components as used with a customized low-cost simple treatment method [8]

To conclude, a concrete based on recycled aggregates could be used with a maximum release rate of $25-30 \%$ without addition and $50 \%$ with the addition of superplasticizer additives.

This study focused on mechanical characterization, the goal being an ordinary building plan under current conditions.

For more complicated projects and more developed concretes, more in-depth studies must be established based on:

- The quality of the aggregates to be used

- The aggregate / cement interaction

- $\quad$ The results of the mechanical tests 
- The results of durability tests; these tests are essential for buildings with a lifespan of more than 50 years or buildings in environments liable to attack concrete.

\section{Conflict of Interest}

The authors declare no conflict of interest.

\section{References}

[1] M.R. Riaz, R.Hameed, M.Ilyas, A.Akram, Z.A. Siddiqi , "Mechanical Characterization of Recycled Aggregate Concrete" , Pakistan. Journal of Engineering \& Applied Sciences. 16, 25-32,2015.

[2] M. Malešev, V.Radonjanin, G.Broćeta, "properties of recycled aggregate concrete, Contemporary Materials", 2 , 239-249 ,2014, doi: 10.7251/COMEN1402239M .

[3] M. Chakradhara Rao, S.K. Bhattacharyya, S.V. Barai , "Influence of field recycled coarse aggregate on properties of concrete", Materials and Structures, 44, 205-220, 2011, doi:10.1617/s11527-010-9620-x.

[4] J. Xiao,W. Li, Y.Fan, X. Huang, A, "overview of study on recycled aggregate concrete in China ( 1996-2011)", Construction and Building Materials, 31, 364-383 , 2012, doi:10.1016/j.conbuildmat.2011.12.074.

[5] S.C. Kou, C.S.Poon, "Long-term mechanical and durability properties of recycled aggregate concrete prepared with the incorporation of fly ash", Cement and Concrete Composites, 37, 12-19, 2013, doi:10.1016/j.cemconcomp.2012.12.011.

[6] C. Thomas, J.Setién, J.A.Polanco, P.Alaejos, M.Sanchez De Juan, "Durability of recycled aggregate concrete", Construction Building Materials, 40, 10541065,2013 , doi: 10.1016/j.conbuildmat.2012.11.106.

[7] H. Chbani, B. Saadouki, M. Boudlal, M. Barakat, "Formulation of Ordinary Concrete using the Dreux-Gorisse Method", Procedia Structural Integrity, 28, 430-439, ,2020 doi: 10.1016/j.prostr.2020.10.050

[8] G. Dimitrou, P.Savva, M.F.Petrou , "Enhancing mechanical and durability properties of recycled aggregate concrete", Construction Building Materials, 158, 228-235 , 2018, doi: 10.1016/j.conbuildmat.2017.09.13 . 